\title{
An investigation of risk factors associated with respiratory syncytial virus infection in a sample of infants and young children from baghdad
}

\author{
Suha Hanoon Ali Arwa Mujahid Abdullah Al-Shuwaikh* Hala Sameh Arif** \\ Al Emamain Al-Kadhemain Medical City Hospital \\ * Microbiology Department/ College of Medicine/ Al-Nahrain University \\ ** Pediatrics Department/ College of Medicine/ Al-Nahrain University \\ E-mail : arwa_alshwaikh_2004@yahoo.com , arwa.mujahid@colmed-alnahrain.edu.iq
}

\begin{abstract}
Background: Human Respiratory Syncytial virus (hRSV) is one of the major causes of viral respiratory tract infection in infants and young children.

Aim of study: The aim of this study was to determine the risk factors associated with hRSV infection. Objective: This study included 100 hospitalized infants and young children with chest infection (39 female and 61 male) aged from (1) to (24) months, their mean age (6.87) months.

Material and methods: Nasopharyngeal/throat swabs specimens were collected over a three-month winter period from January to April, 2017. hRSV was determined by reverse transcription polymerase chain reaction (RT-PCR).

Results: The highest percentage of hRSV RNA $(\mathbf{5 6 . 8 1 \%})$ was observed in the age group less than 6 months, followed by $(27.27 \%)$ and $(15.91 \%)$ in the age group 6-12 months and 12-24 months, respectively, which mean that $(84 \%)$ of $h R S V$ infections were under 12 months of age. Regarding the type of feeding, about (84\%) of hRSV infections were positive in patients with bottle feeding which indicated that the role of breastfeeding in preventing hRSV infection and hospitalization is undisputed, Results showed that there was no significant association between these risk factors and the occurrence of hRSV infection $(P>0.05)$.

Conclusion: The hRSV-RNA is equally distributed between patients exposed and not exposed to smoking (50\%).
\end{abstract}

Key words: hRSV, RT-PCR, risk factors, infants and young children.

\section{Introduction}

The Paramyxoviridae family (1). HRSV was recovered first from children in Baltimore and suggested the name respiratory syncytial virus to reflect the giant syncytia which formed in tissue culture (2). This virus has single serotype with two major antigenic subgroups (A and B) that are distinguished by variation in the G-glycoprotein $(3,4,5)$. Children when initially infected with a group A - hRSV that become relatively protected against group A infection, while re-infections are more likely to be due to heterologous group B hRSV (6).

HRSV is the main cause of upper respiratory tract infections (URTI) and lower respiratory tract infections (LRTI) in infants and young children, and are a major public health problem in this age group $(7,8,9)$. Today it is in charge of $45 \%-90 \%$ of episodes of bronchiolitis, $15 \%-35 \%$ of pneumonia, $6 \%-8 \%$ of croup, and is also a cause of apnea and otitis media $(8,10,11)$. Approximately two-thirds of infants are infected with hRSV during the first year of life and $90 \%$ have been infected one or more times by two years of age $(8,9)$.

World-wide, RSV directly or indirectly contributes to the death of between 600000 and 100000 infants and children under the age of 5 years (7). Mortality due to acute respiratory tract infection (ARI) is high in developing countries which may reach 1000 or more per 100000 live births compared to 30-40 per 100000 live births in industrialized nation. The WHO estimate that in 1990 ARI tragically caused 13 million children die each year, 4.3 million children die from ARI, mostly pneumonia, every year in developing countries. Two- third occur in children under one year of age (12).

Although prevention and treatment of hRSV infection are still limited, the antiviral drug ribavirin has been restricted to immunocompromised patients with severe RSV disease. Palivizumab, a humanized monoclonal antibody directed against the F protein of RSV and RSV-IGIV (RespiGam), an IgG immune globulin with high concentrations of RSV neutralizing antibody, have been used to prevent severe lower respiratory tract infections caused by hRSV in high-risk patients (7). 


\section{Materials and Methods}

Subject: In this cross-sectional study, 100 infants and young children were enrolled (39 female and 61 male) aged from (1) month to (24) months, their mean age was (6.87) months, they required hospital admission at the Pediatric Department in AL-Imammain AL-Kadhimain Medical City Hospital, Central Teaching Pediatric Hospital, and AL-Kadhimiya Pediatric Hospital in Baghdad-Iraq. Samples collection was carried out from January to April, 2017. The study was approved by the Institutional Review Board (IRB) at AlNahrain College of Medicine and an informed consent was obtained from either the mother or the father of the child before included in this study. Exclusion criteria included immunosuppressive children and whom taken palivizumab for prophylaxis or treatment.

Specimens collection: Nasopharyngeal/throat swabs were collected and combined in universal transport medium (UTM) tube (Cat. No. 80346C, Copan, Italy). Each sample was aliquot and stored at $\left(-80^{\circ} \mathrm{C}\right)$ until testing by RT-PCR for detection of hRSV- RNA by hRSV 298/550 IC Kit (Sacace Biotechnologies, Italy).

Nucleic acid extraction: Nasopharyngeal/throat processed samples were thawed and centrifuged at $10000 \mathrm{~g} / \mathrm{min}$ for $5 \mathrm{~min}$, after that the supernatant was discarded except $100 \mu \mathrm{l}$ of the solution which leaved to be used in re-suspension of the pellet for RNA extraction. The Ribo-Sorb nucleic acid extraction kit (Sacace Biotechnologies, Italy) was used for isolation and purification of RNA/DNA from samples according to manufacturer's instructions. Then the RNA extracts were reverse transcript to cDNA according to the manufacturer's instructions. Each obtained cDNA sample was diluted (1:2) with Tris-EDTA buffer solution and stored at $\left(-20^{\circ} \mathrm{C}\right)$ until cDNA amplification. The amplification kit (hRSV 298/550 IC) contains an internal control which used in the isolation procedure and serves as an amplification control for each specimen and to identify possible reaction inhibition. Negative and positive controls were extracted, reverse transcribed, and amplified in each batch of samples tested by PCR.

cDNA amplification: DNA amplification reactions were carried out according to manufacturer's instructions in three steps: first initial denaturation at $95{ }^{\circ} \mathrm{C}$ for $5 \mathrm{~min}(1 \mathrm{cycle})$ and then the DNA amplification by sequentially heated for denaturation of DNA template at $95^{\circ} \mathrm{C}$ for 45 sec., annealing at 56 ${ }^{\circ} \mathrm{C}$ for $45 \mathrm{sec}$. and extension at $72{ }^{\circ} \mathrm{C}$ for $45 \mathrm{sec}$. ( 42 cycles) and then for addition final extension at $72{ }^{\circ} \mathrm{C}$ for $5 \min (1$ cycle).

Interpretation of the results: Ten $\mu$ of PCR products were subjected to electrophoresis in agarose (2\%) in the presence of ethidium bromide and visualized under UV trans illuminator. The sample is considered to be positive for hRSV-RNA if the band of $298 \mathrm{bp}$ is observed on agarose gel. The presence of a $550 \mathrm{bp}$ fragments indicated a positive result for internal control (IC) specific amplified DNA fragments as showed in Figure (1).

Statistical Analysis: The data were analyzed using Statistical Package for the Social Sciences program (SPSS), versions 21 for windows software package release 2013. Chi square test $\left(\chi^{2}\right)$ was used to estimate the association between two categorical variables. Level of significance of $\leq 0.05$ was considered as significant.

\section{Results}

Risk factors for the spread of hRSV infection among infants and young children with chest infection were analyzed. Data were collected by using a special questionnaire including the age, gender, type of feeding, exposure to smoke, the number of family members and underlying medical disease as shown in Table (1). The rate of hRSV-RNA positivity tended to be decreased with increase age, hRSV-RNA demonstrated in much higher percentage (56.81\%) in the age group 0-6 months compared to the age group 6-12 months $(27.27 \%)$, which mean that $84 \%$ of hRSV infections are under 12 months of age and $(15.91 \%)$ of hRSV infections are in the age groups between (12-24) months; however, there was no statistically significant association between hRSV-RNA positivity and the different age group $(P>0.05)$.

The current study showed that hRSV-RNA positivity in males higher than in females with percentage (52.27\% vs. $47.73 \%$, respectively) but this difference was not statistically significant $(P>0.05)$. The males to female's ratio were 1.5:1. Three types of feeding enrolled in this study, the results showed higher percentage of hRSV-RNA positive patients with bottle feeding $(59.09 \%)$ than mixed feeding $(25.0 \%)$ and breastfeeding $(15.19 \%)$; however, there was no statistically significant association between hRSV-RNA positivity and type of feeding $(P>0.05)$. Also, there was no statistically significant association between hRSV-RNA positivity and exposure to smoking $(P>0.05)$.

Regarding the number of family members, this study demonstrated that 19 out of 44 (43.18\%) of hRSVRNA positive patients had a number of family members $<5$ in home family, while 25 out of $44(56.82 \%)$ of hRSV-RNA positive patients had $\geq 5$ members in home family $(P>0.05)$. This study showed that hRSV was detected in 8 out of 44 (18.18\%) of patients with congenital heart disease (CHD), in 2 out of 44 (4.55\%) of patients with Down syndrome, in 4 out of $44(9.09 \%)$ of patients with asthma as shown in Table (1). 
Figure (1): PCR products of hRSV L gene. Lane1, 100-3000bp ladder; Lane 2, hRSV cDNA serves as positive control for amplification; Lane 3, DNA- buffer serves as negative control for amplification; Lane 4, 6 and 7 are hRSV-RNA positive samples; Lane 5 is hRSV-RNA negative sample

Table (1): Frequency of hRSV-RNA infection in relation to risk factors

\begin{tabular}{|c|c|c|c|c|}
\hline \multirow[b]{2}{*}{ Risk factors } & \multirow{2}{*}{$\begin{array}{c}\text { No. of patients } \\
(\%)\end{array}$} & \multicolumn{2}{|c|}{ hRSV-RNA status } & \multirow[b]{2}{*}{ Statistic } \\
\hline & & $\begin{array}{c}\text { No. of hRSV-RNA } \\
+ \text { ve }(\%)\end{array}$ & $\begin{array}{l}\text { No. of hRSV- } \\
\text { RNA -ve (\%) }\end{array}$ & \\
\hline \multicolumn{5}{|l|}{ Age groups } \\
\hline < 6 months & $62(62 \%)$ & $25(56.82 \%)$ & $37(66.07 \%)$ & \multirow{4}{*}{$\begin{array}{l}X^{2}=2.06 \\
P=0.356\end{array}$} \\
\hline 6-12 months & $27(27 \%)$ & $12(27.27 \%)$ & $15(26.79 \%)$ & \\
\hline 12-24 months & $11(11 \%)$ & $7(15.91 \%)$ & $4(7.14 \%)$ & \\
\hline Total & $100(100 \%)$ & $44(100 \%)$ & $56(100 \%)$ & \\
\hline \multicolumn{5}{|l|}{ Gender type } \\
\hline Male & $61(61 \%)$ & $23(52.27 \%)$ & $38(67.86 \%)$ & \multirow{3}{*}{$\begin{array}{l}X^{2}=2.52 \\
P=0.113\end{array}$} \\
\hline Female & $39(39 \%)$ & $21(47.73 \%)$ & $18(32.14 \%)$ & \\
\hline Total & $100(100 \%)$ & $44(44 \%)$ & $56(56 \%)$ & \\
\hline \multicolumn{5}{|l|}{ Type of feeding } \\
\hline Breastfeeding & $14(14 \%)$ & $7(15.91 \%)$ & $7(12.5 \%)$ & \multirow{4}{*}{$\begin{array}{l}X^{2}=0.53 \\
P=0.767\end{array}$} \\
\hline Bottle feeding & $63(63 \%)$ & $26(59.09 \%)$ & $37(66.07 \%)$ & \\
\hline Mixed feeding & $23(23 \%)$ & $11(25.0 \%)$ & $12(21.43 \%)$ & \\
\hline Total & $100(100 \%)$ & $44(100 \%)$ & $56(100 \%)$ & \\
\hline \multicolumn{5}{|c|}{ Exposure to smoking } \\
\hline Yes & $53(53 \%)$ & $22(50 \%)$ & $31(55.36 \%)$ & \multirow{3}{*}{$\begin{array}{l}X^{2}=0.28 \\
P=0.594\end{array}$} \\
\hline No & $47(47 \%)$ & $22(50 \%)$ & $25(44.64 \%)$ & \\
\hline Total & $100(100 \%)$ & $44(100 \%)$ & $56(100 \%)$ & \\
\hline \multicolumn{5}{|c|}{ Number of family members } \\
\hline$<5$ in home family & $52(52 \%)$ & $19(43.18 \%)$ & $33(58.93 \%)$ & \multirow{3}{*}{$\begin{array}{l}X^{2}=2.45 \\
P=0.118\end{array}$} \\
\hline$\geq 5$ in home family & $48(48 \%)$ & $25(56.82 \%)$ & $23(41.07 \%)$ & \\
\hline Total & $100(100 \%)$ & $44(100 \%)$ & $56(100 \%)$ & \\
\hline \multicolumn{5}{|c|}{ Underlying Medical Condition } \\
\hline \multicolumn{5}{|c|}{ Congenital Heart Disease } \\
\hline Yes & $13(13 \%)$ & $8(18.18 \%)$ & $5(8.93 \%)$ & \multirow{3}{*}{$\begin{array}{l}X 2=1.68 \\
P=0.172\end{array}$} \\
\hline No & $87(87 \%)$ & $36(81.82 \%)$ & $51(91.07 \%)$ & \\
\hline Total & $100(100 \%)$ & $44(100 \%)$ & $56(100 \%)$ & \\
\hline \multicolumn{5}{|l|}{ Down Syndrome } \\
\hline Yes & $4(4 \%)$ & $2(4.55 \%)$ & $2(3.57 \%)$ & \multirow{3}{*}{$\begin{array}{l}X 2=0.06 \\
P=0.805\end{array}$} \\
\hline No & $96(96 \%)$ & $42(95.45 \%)$ & $54(96.43 \%)$ & \\
\hline Total & $100(100 \%)$ & $44(100 \%)$ & $56(100 \%)$ & \\
\hline \multicolumn{5}{|l|}{ Asthma } \\
\hline Yes & $5(5 \%)$ & $4(9.09 \%)$ & $1(1.79 \%)$ & \multirow{3}{*}{$\begin{array}{l}X^{2}=2.77 \\
P=0.096\end{array}$} \\
\hline No & $95(95 \%)$ & $40(90.91 \%)$ & $55(98.21 \%)$ & \\
\hline Total & $100(100 \%)$ & $44(100 \%)$ & $56(100 \%)$ & \\
\hline
\end{tabular}




\section{Discussion}

The present study describes the frequency of hRSV in infants and young children $\leq 2$ years old. Regarding age, hRSV infection was varied from 25 cases in the age group less than 6 months to 7 cases in the age group (12-24) months Table (1). The rate of hRSV-RNA positivity tended to be decreased with increase age; however, the current study revealed a non-significant association between age groups and hRSV-RNA detection. This result is in accordance with that reported by other studies $(13,14)$. This might be due to the fact that these infants and young children have immature immune system and they were in daily contact with other children which could be act as a source of infection, other reasons include narrow airways, incomplete development of the lungs and relatively short bronchial tree $(6,15,16)$. However, other founded that high frequency of hRSV infection in children more than one year was statistically significant $(15,17,18,19,20)$. On comparing the gender distribution among infants and young children with hRSV-RNA infection, males to female's ratio was 1.5:1. Although, there was no significant association between gender and hRSV-RNA detection, the hRSV positive male was higher than female ( $252.27 \%$ vs. $47.73 \%$, respectively). This finding is in agreement with the results reported by many studies $(2,4,5,9,10,12,15,19,20,21,22,23,24,25)$. The reason for that seems to be the anatomic nature that boys have shorter and narrower airways and are more likely to develop bronchial obstruction in case of hRSV infection (6). Another researcher found that the IL-9 genetic polymorphism (rs2069885) has an effect on the risk of severe hRSV infection in boys than girls (26). Some study $(17,27)$ reported a significant association between gender and hRSV infection.

Considering type of feeding, current study showed that hRSV infection demonstrated in higher percentage in patients with bottle feeding (84\%), while low percentage demonstrated in patients with breastfeeding $(15.91 \%)$ but there was no significant association between the type of feeding and hRSV infection. These finding in agreement with the results founded by $(4,8,12)$ whom found that there was no statistical association between ARI and late weaning time, but some studies found that breastfeeding significantly decrease the risk of having bronchiolitis by 5 times compared to those on bottle feeding and mixed feeding (5). Possible explanation for this partial protective of breastfeeding includes: that lymphocytes in the colostrums or milk that are sensitized to hRSV and colonize in the nasopharynx of infants, or to stimulation immune response of the infants by transfer of sensitized $\mathrm{T}$ cells or of antigen on macrophages or may be because breast milk causes suppress to the IgE response which may be important in the pathogenesis of bronchiolitis or may be another factors such: home environment, poor hygiene and maternal care $(4,8)$. Some studies found that hRSV-IgA and lactoferrin in the breast milk which promotes maturation probably through the influence of prolactin, or breast milk protection against ARI is not universally conferred by passive transfer of humeral immunity (6).

On the other hand, comparison of infants and young children with or without exposure to parental smoking showed that hRSV infection was equally distributed between these two groups (50\%). There was no significant association between children exposure to smoking and hRSV infection. This finding was in agreement with that mentioned by other studies $(8,12,19,28)$ but in disagreement with $(4,5,6,7)$. A study found several effects of passive smoking and biomass fuels in infants and young children that increasing the rate of cross-infection from the parental smokers, mediating an allergic reaction, or by causing irritation of the infantile passages than facilitate the spread of infection to the lower respiratory tract (8).

Regarding household crowding condition, the result showed that the hRSV infection in children with a family members $\geq 5$ was more liable than children with family members $<5(56.82 \%$ vs. $43.18 \%$, respectively). There was no significant association between the number of family members and hRSV infection. This result coincided with that founded by (8) in India, who found that housing type and socioeconomic variables such as parent education and monthly income were lower in slums than others but there was no significant association between household crowding and ARI incidence (8). Some studies found that the number of children residents in the home family associated with hRSV-related pneumonia in children younger than 6 years and increased the exposures to allergens, respiratory irritants and infectious agents (5).

Underlying disease was another risk factor that under investigation in this study. In according to CHD, current study showed no significant association between CHD and hRSV infection. This finding is in accordance with that reported by $(2,8,19,20)$. Checchia, et al. (2016) reported that infants and young children with CHD are a high risk for infection with hRSV because anatomical cardiovascular lesions which can cause pulmonary hypertension leading to increased ventilation-perfusion mismatch than ultimately and hypoxia (29). Another study conducted by (25) found that association between infants and young children with CHD and nosocomial hRSV infection (25).

Also patients with Down syndrome showed no significant association with hRSV infection. Similar results observed by $(6,19)$, but $(30)$ was found that babies born with Down's syndrome, cystic fibrosis and cerebral palsy are a higher risk of hospitalization with hRSV infection (30). Another study reported by (2) found that children with Down syndrome have an increased rate of co-morbidities with both pulmonary hypertension and CHD; another mechanism associated with Down's syndrome hypotonia, more injury-prone lungs, an abnormal upper respiratory anatomy, and altered lung growth. Immunological impairment was 
demonstrated associated with Down's syndrome including defects in adaptive and intrinsic immunity, diminished numbers of $\mathrm{B}$ and $\mathrm{T}$ cells due to abnormal thymus function, decreased numbers of lymphocyte and responses to stimulations, reduced phagocytosis by neutrophils, and lower serum immunoglobulin levels (2).

Regarding asthma, current study showed that hRSV infection in cases without asthma was higher $(90.91 \%)$ than cases with asthma $(9.09 \%)$ and this due to the low number of asthmatic patients included in this study. However, there was no significant association between asthmatic patients and hRSV infection. Rida, (2011) demonstrated several factors correlate between hRSV and asthma; such as the genetic background of the infant, neural control leading to sustained bronchial hyper-reactivity, intermittent changes in the host cellular immune responses environmental conditions and exposure to endotoxin and recurrent wheezing, timing of hRSV infection with exposure to allergen (5).

In conclusion, this study has demonstrated that the importance of hRSV as a major cause of acute respiratory tract infection in hospitalized infants and young children with chest infection in Baghdad-Iraq where there was no vaccines available till now.

\section{Acknowledgments}

The authors thank the resident physicians at AL-Imammain AL-Kadhimain Medical City Hospital, Central Teaching Pediatric Hospital, and AL-Kadhimiya Pediatric Hospital for their help in samples collection. This work was done at Al-Nahrain University, College of Medicine, and Microbiology Department.

Contributors: Arwa Mujahid Al-Shuwaikh and Suha Hanoon Ali are co-first authors and equally contributed to this paper. Dr. Arwa Mujahid Al-Shuwaikh design and wrote this manuscript, Suha Hanoon Ali performed all the laboratory work, Dr. Hala Sameh Arif was involved in the patient's management and helped in specimens collection. All the authors have read and approved the final version of this manuscript.

\section{References}

1. Falsey AR, Formica MA, Walsh EE. Diagnosis of Respiratory Syncytial Virus Infection: Comparison of Reverse Transcription-PCR to Viral Culture and Serology in Adults with Respiratory Illness. J. of Clinical Microbiology.(2002); 40(3):817-820.

2. Lee YI, Peng CC, Chiu NC. et al. Risk factors associated with death in patients with severe respiratory syncytial virus infection. J. of Microbiology, Immunology and Infection.(2016); 49 (5): 737-42.

3. Mackman RL, Sangi M, Sperandio D. et al. Discovery of an Oral Respiratory Syncytial Virus (RSV) Fusion Inhibitor (GS-5806) and Clinical Proof of Concept in a Human RSV Challenge Study. J. Med. Chem.(2015); 58(4):1630-43.

4. Al bargish KA, Hasony HJ. Respiratory syncytial virus infection among young children with acute respiratory tract infection in Iraq. Eastern Mediterranean Health J..(1999); 5 (5): 941-948.

5. Rida MF. Risk factors for Respiratory Syncytial Virus (RSV) bronchiolitis in children: a hospital based study. The Iraq Postgraduate Medical J..(2011);10(3):305-10.

6. Sommer C, Resch B, Simões EA. Suppl 2: Risk Factors for Severe Respiratory Syncytial Virus Lower Respiratory Tract Infection. The open microbiology j..(2011); 5:144.

7. Savić N, Janković B, Minić P, Vasiljević Z, Sovtić A, Pejić K, Sarajlija A, Gazikalović S. Clinical characteristics of respiratory syncytial virus infection in neonates and young infants. Vojnosanitetski pregled.(2011); 68(3): 220-4.

8. Etiler N, Velipasaoglu S, Aktekin M. Incidence of acute respiratory infections and the relationship with some factors in infancy in Antalya, Turkey. Pediatrics international.(2002); 44 (1): 64-9.

9. Al-Marzoqi AH, Al Taee ZM, Hussein HJ. Respiratory Syncytial Virus Infection among Children under 2 Years Old in Hillah City, Iraq. J. of Natural Sciences Research.(2013); 3(3):32-35.

10. Al Masri M, Papa A, Souliou E. et al. Respiratory Syncytial Virus Infection in Hospitalized Children Older Than 2 Years with Community-Acquired Pneumonia, Hippokratia.(2013); 17 (2): 146-149.

11. Bicer S, Giray T, Çöll D. et al.. Virological and clinical characterizations of respiratory infections in hospitalized children. Italian j. of pediatrics.(2013); 39(1):22.

12. Al-bahadily AJ, Al-Omrani AM , Atiya AA. Hypertonic 3\% Saline in Comparison with $0.9 \%$ (Normal) Saline in Treatment of Acute Bronchiolitis. Int J Pediatric.(2017); 5(1): 4209-16.

13. AL-Bashar SH, Badawy AS, Mohammed BAR. Real time-PCR, ELISA, as identification methods for Detection respiratory syncytial virus in children. Tikrit J. of Pure Science.(2017); 22 (2):1813 - 1662.

14. Odisho SM, Al-Bana AS, Yaassen NY. Isolation and identification of Respiratory syncytial virus from Infants with histopathological studies of the isolated virus on experimental animals. Iraqi J. Med. Sci.(2010); 8 (1):2-10. 
15. Yousif T, Khaleq B. Epidemiology of acute respiratory tract infections (ARI) among children under five years old attending Tikrit General Teaching Hospital. Middle East J. of Family Medicine.(2006); 14(3):14852.

16. Yilgwan CS, John C, Abok II. et al.. Pattern of acute respiratory infections in hospitalized children under five years of age in Jos Nigeria. Niger J Paed.(2013); 40 (2): $150-153$.

17. Meqdam MM , Subaih SH. Rapid Detection and Clinical Features of Infants and Young Children with Acute Lower Respiratory Tract Infection Due To Respiratory Syncytial Virus. FEMS Immunology and Medical Microbiology.(2006); 47 (1): 129-33.

18. Odisho SM, Al-Bana AS, Yaassen NY. Detection of Respiratory syncytial virus infection in a sample of infants in Iraq. Iraqi J. of Medical Sciences.(2009); 7(4): 11-19.

19. Halasa N, Williams J, Faouri S. et al.. Natural history and epidemiology of respiratory syncytial virus infection in the Middle East: Hospital surveillance for children under age two in Jordan. Vaccine.(2015); 33(47):6479-87.

20. Aziz TAG, Hussain AH. Seroprevalence on anti-Respiratory Syncytial Virus antibodies hospitalized patients with acute respiratory tract infections in Sulaimani Governorate/Iraq. JSMC.(2014); 4(1): 47-53 .

21. $\mathrm{Al}$ - Shami JAJ, Al - Obaidi N. Review of wheezing in children in maternity and children teaching hospital in Al-Diwaniyah/Iraq. Babylon Med. J. (2009); 6 (3-4): 477-483.

22. Tabatabai J, Prifert C, Pfeil J. et al. Novel Respiratory Syncytial Virus (RSV) Genotype ON1 Predominates in Germany during Winter Season 2012-13. PLoS ONE.(2014); 9(10): e109191.

23. Khalil SO, Enan KA, Salim B, Elkhidir IM. Detection and Molecular Characterization of Respiratory Syncytial Virus (RSV) in Children with Respiratory Signs in Khartoum State, Sudan 2011-2012. American J. of Infectious Diseases and Microbiology.(2015); 3(1):6-13.

24. Zahran WA, Makled AF, Salama AA. et al. Comparison of Reverse Transcription-PCR and Viral Culture for detection of Respiratory Syncytial Virus in Young Children: Relation to Epidemiological and Clinical Findings. Egyptian J. of Medical Microbiology (EJMM).(2017); 26 (2): 27-36.

25. Oladokun R, Muloiwa R, Hsiao N. et al. Clinical characterisation and phylogeny of respiratory syncytial virus infection in hospitalised children at Red Cross War Memorial Children's Hospital, Cape Town. BMC infectious diseases.(2016); 16 (1): 236.

26. Bont L, Checchia PA, Fauroux B. et al.. Defining the epidemiology and burden of severe respiratory syncytial virus infection among infants and children in western countries. Infectious diseases and therapy. (2016);5(3): 271-98.

27. Al-Toum R, Bdour S, Ayyash H. Epidemiology and Clinical Characteristics of Respiratory Syncytial Virus Infections in Jordan. J. of tropical pediatrics.(2006); 52 (4): 282-7.

28. Hall CB, Weinberg GA, Iwane MK. et al. The burden of respiratory syncytial virus infection in young children. New England J. of Medicine.(2009); 360 (6): 588-98.

29. Checchia PA, Paes B, Bont L. et al. Defining the risk and associated morbidity and mortality of severe respiratory syncytial virus infection among infants with congenital heart disease. Infectious diseases and therapy.(2017); 1-20.

30. Murray J, Bottle A, Sharland M. et al. Risk factors for hospital admission with RSV bronchiolitis in England: a population-based birth cohort study. PloS one.(2014); 9(2): e89186. 